Article

\title{
Hot-Dip Aluminizing on AISI F55-UNS S32760 Super Duplex Stainless Steel Properties: Effect of Thermal Treatments
}

\author{
Andrea Francesco Ciuffini * (1D), Silvia Barella (1D), Cosmo Di Cecca, Andrea Gruttadauria, \\ Davide Mombelli and Carlo Mapelli \\ Dipartimento di Meccanica, Politecnico di Milano, via La Masa 34, 20156 Milano, Italy; \\ silvia.barella@polimi.it (S.B.); cosmo.dicecca@polimi.it (C.D.C.); andrea.gruttadauria@polimi.it (A.G.); \\ davide.mombelli@polimi.it (D.M.); arlo.mapelli@polimi.it (C.M.) \\ * Correspondence: andreafrancesco.ciuffini@polimi.it; Tel.: +39-340-125-3162
}

Received: 21 October 2017; Accepted: 22 November 2017; Published: 25 November 2017

\begin{abstract}
The behavior of super duplex stainless steels AISI F55-UNS S32760 in hot-dip aluminizing process has been studied, investigating the influence of cold working and of different initial microstructures obtained through a preliminary thermal treatment. The microstructural features examined are the secondary austenite precipitation, the static recovery of ferrite and the thermal dissolution of austenite within ferritic matrix. The hot-dip aluminizing temperature has been optimized through sessile drop tests. The treatment has been performed at $1100{ }^{\circ} \mathrm{C}$ for $300 \mathrm{~s}, 900 \mathrm{~s}$ and $2700 \mathrm{~s}$. A strong chemical interaction occurs, generating intermetallic compounds at the interface. Molten aluminum interacts exclusively with the ferritic phase due to its much higher diffusivity in this phase coupled with its marked ferrite-stabilizer behavior. Thus, the influence of cold working is not remarkable, since the strains are mainly allocated by austenitic phase. The diffusivity of aluminum increases due to lattice defects thermally generated and, mainly, to influence given by grain boundaries, multiplied by secondary austenite precipitation, which act as short-circuit diffusion paths. Ni and $\mathrm{Cr}$ contents in the ferritic matrix have an influence but not highly relevant. Then, the best starting condition of the super duplex stainless steel substrates, to obtain a thick interfacial layer, are the thermal annealing at $1080{ }^{\circ} \mathrm{C}$ for $360 \mathrm{~s} / \mathrm{mm}$ after a solution thermal treatment at $1300{ }^{\circ} \mathrm{C}$ for $60 \mathrm{~s} / \mathrm{mm}$.
\end{abstract}

Keywords: super duplex stainless steels; thermal treatment; hot-dip aluminizing; steel aluminum interface; diffusion

\section{Introduction}

Aluminized steel strips possess strength and plasticity, given by the substrate material, and corrosion resistance warranted by the coating. Thus, they have found application in many industries: building, motorization, heat engineering, and household appliances production.

Further, heat resistant stainless steels, widely used in petroleum, chemical, nuclear and other applications, obtain a beneficial effect from aluminum: the high temperature oxidation resistance is recognized as providing a protective alumina surface layer during high temperature exposure. These aluminide coatings result in a superior resistance to oxidation, carburization and sulfidation [1-6].

Moreover, the management of all hydrogen isotopes is an increasing business in recent years both in energy storage technology and for the development of Deuterium-Tritium (D-T) fusion plants, which is extremely important leading scientific research. Hydrogen barriers will be an integral part of the hydrogen isotopes management system, since they are necessary to limit kinetically the 
achievement of tritium-contaminated effluents, high tritium concentrations in work areas and/or hydrogen embrittlement of metals [7-11].

The present aluminizing technologies include hot-dipping, physical vapor deposition, solid powder route, pack cementation, reaction synthesis and paste calorized method. Hot-dip aluminizing results one of the most practical processes, taking into account the quality of the aluminized layer, environmental protection, economy and convenience for mass production [11-16].

This process has been successfully used to generate a layer of aluminum on the surface of steel substrate; when wetting the surface of steel substrate, aluminum diffuses into steel to form Fe-Al intermetallic compounds [5]. This intermetallic layer dominates the performance of the substrate uncoated material and its thickness affects the resulting properties. Thus, a thicker hot-dipped layer is suitable, especially for those applications where aluminum and aluminide coatings act as barriers $[9,17]$.

In the last decades, hot-dip aluminizing has been applied to carbon steels, low-alloyed steel, and stainless steels, but not to super duplex stainless steels (SDSS). The mechanical properties of SDSSs also reach high values, compared to competitor grades [15]. These steel grades are actually used in oil and gas, chemical, and nuclear industries, and, in all those applications, corrosion resistance plays a key role. Thus, hot-dip aluminizing of this steel grade is extremely interesting for future applications $[18,19]$.

Super duplex stainless steels are materials extremely suitable to resist chloride-containing environments, since, originally, they were developed to resist corrosion in sea water. The most common are AISI F53-UNS S32750 and AISI F55-UNS S32760, reaching roughly the same or even better corrosion resistance than superaustenitic stainless steel grades [20-24].

In this study, AISI F55-UNS S32760 super duplex stainless steel has been aluminized with commercially pure aluminum. Hot-dip aluminizing temperature has been chosen as $1100{ }^{\circ} \mathrm{C}$, through sessile drop tests, and the treatment has been executed for $300 \mathrm{~s}, 900 \mathrm{~s}$ and $2700 \mathrm{~s}$. Further, the influence on hot-dip aluminizing of cold working and microstructural features, such as secondary austenite precipitation, the static recovery of ferrite and the thermal dissolution of austenite within ferritic matrix, have been investigated.

\section{Experimental Procedure}

The commercially pure aluminum grade, used for the hot-dip aluminizing process, is the AA 1200 alloy, which is featured by Si 0.7 wt. \%, Fe 0.3 wt. \%, Zn 0.1 wt. \%, Cu + Mn 0.05 wt. \% and Al bal. chemical composition. Samples were drawn from a commercial AISI F55 (Cr 24-26 wt. \%, Ni 6-8 wt. \%, Mo 3-4 wt. \%, W 0.5-1 wt. \%, Cu 0.5-1 wt. \%, Mn $<1$ wt. \%, Si < 1 wt. \%, C $<0.03$ wt. \%, N 0.2-0.3 wt. \% and Fe bal.), also known as UNS S32760, cold drawn bar with the indicative dimensions of $25 \mathrm{~mm} \times$ $25 \mathrm{~mm} \times 10 \mathrm{~mm}$. Several samples have been taken as reference and named as "CD" in the following. Further, the other specimens were subjected to thermal treatments, modifying their microstructure. First, a solution thermal treatment has been executed at $1300{ }^{\circ} \mathrm{C}$ with holding times of $60 \mathrm{~s}$ per millimeter and all specimens have been water quenched. This thermal treatment has been performed to obtain a duplex $\alpha$-ferritic and $\gamma$-austenitic microstructure, avoiding the formation of any undesired secondary phase [25]. This thermal treatment eliminates any residual stress and deformation pattern, originated by previous forming process. This solution thermal treatment also achieves the supersaturation of $\gamma$-former elements within the $\alpha$-ferritic phase. Chemical and thermal homogenization is ensured by the holding time, for the dimensions featuring the specimens. Afterwards, it has been executed an annealing thermal treatment at $1080{ }^{\circ} \mathrm{C}$ for 72,210 or $360 \mathrm{~s} / \mathrm{mm}$ of holding time. The corresponding specimens will be designated as: "A72", "A210" and "A360", respectively [26,27]. This thermal treatment reproduces the hot-working temperature, avoiding the precipitation of the detrimental secondary phases. Finally, all samples have been water quenched. Further, two sets of specimens have been annealed at $1300{ }^{\circ} \mathrm{C}$ and $1400{ }^{\circ} \mathrm{C}$ for $72 \mathrm{~s} / \mathrm{mm}$ and water quenched, to estimate the effect of the solubilization thermal treatment temperature [28]. These samples will be designated as "S1300" and "S1400". Finally, to assess the influence of strain and cold deformation, two set of samples have been 
cold rolled with $60 \%$ and $90 \%$ of reduction ratio. According to the low impressed strain or the high impressed strain, samples will be appointed in the following as "LS" and "HS", respectively.

All samples have been polished with a 2500-grit diamond abrasive (PRESI, Eybens, France).

Few reference samples have been used to perform a trial sessile drop test, to identify the best hot-dip aluminizing temperature. The tests have been executed following the ASTM D7334-13 standard (according to the practice 4.2.2), holding at the test temperature both the AISI F55 substrate and the liquid aluminum. The trial temperatures are: $700{ }^{\circ} \mathrm{C}, 800^{\circ} \mathrm{C}, 900{ }^{\circ} \mathrm{C}, 1000{ }^{\circ} \mathrm{C}, 1100{ }^{\circ} \mathrm{C}, 1200{ }^{\circ} \mathrm{C}, 1300{ }^{\circ} \mathrm{C}$, and $1400{ }^{\circ} \mathrm{C}$.

The trial sessile drop test identified $1100{ }^{\circ} \mathrm{C}$ as the best hot-dip aluminizing temperature, thus the following tests have been executed at this temperature on every set of specimens for different holding times: $300 \mathrm{~s}, 900 \mathrm{~s}$ and $2700 \mathrm{~s}$.

Specimens have been prepared for optical microscopy (Carl Zeiss AG, Oberkochen, Germany), following the standard ASTM E407-07. Samples have been electrochemically etched at $0.5 \mathrm{~V}$ for $90 \mathrm{~s}$ at $40{ }^{\circ} \mathrm{C}$ in a sodium hydroxide solution $\left(10 \mathrm{~g} \mathrm{NaOH}\right.$ in $\left.100 \mathrm{~mL} \mathrm{H}_{2} \mathrm{O}\right)$ This electrochemical etching highlights the microstructure of the investigated alloy, coloring differently the constituent phases. Compared to other etchants, this electrochemical etching does not completely dissolve the aluminum and the aluminum compounds [29,30]. Afterwards, following the standards ASTM E1245-13 and ASTM E1382-10 (ASTM International, West Conshohocken, PA, USA), the quantitative metallographic analysis has been performed.

The local chemical composition has been acquired through a scanning electron microscope (SEM) (Carl Zeiss AG, Oberkochen, Germany) Zeiss EVO $50^{\circledR}$, using dispersive X-ray microanalysis (SEM/EDS) (INCA Oxford Instrument, Oxford, UK) and secondary electron detector (SEM/SE) (INCA Oxford Instrument, Oxford, UK). Phases have been identified also through electron backscattered diffraction mapping (SEM/EBSD) (INCA Oxford Instrument, Oxford, UK) measurements.

\section{Theory and Calculation}

\subsection{Wetting Contact Angle}

Wetting plays an important role in many industrial processes, such as oil recovery, lubrication, liquid coating, printing, and spray quenching. Measurement of contact angles $(\theta)$ are usually involved in wettability studies as the primary data, which identify the wetting degree, when a solid and liquid interaction occurs (Figure 1). Large contact angles $\left(\theta>90^{\circ}\right)$ correspond to low wettability, generally meaning that wetting the surface is unfavorable, thus, the fluid will minimize its contact with the surface. On the other hand, small contact angles $\left(\theta<90^{\circ}\right)$ correspond to high wettability.

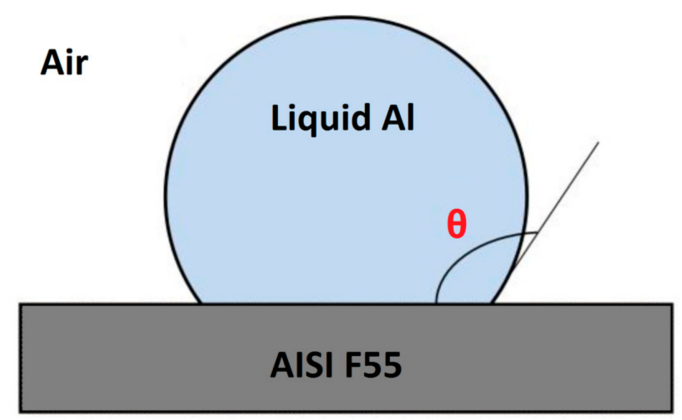

Figure 1. Schematic illustration of contact angles formed by sessile liquid drops on an ideal surface.

Ideally, the shape of a liquid droplet is determined by the surface tension of the liquid, described by Young's equation (Equation (1)). This equation defines the contact angle of a liquid drop on an ideal solid surface as the mechanical equilibrium of three interfacial tensions:

$$
\gamma_{l v} * \cos \theta=\gamma_{s v}-\gamma_{s l}
$$


where $\gamma_{l v}$ represents the liquid-vapor interfacial tension, $\gamma_{s v}$ corresponds to the solid-vapor interfacial tension, $\gamma_{s l}$ is the solid-liquid interfacial tension and $\theta$ represents the contact angle.

Usually, liquid metals are high surface energy liquids, reflecting the high cohesion of metals due to their metallic bonding. These strong interactions, considered as chemical, are one to two orders of magnitude greater than the surface energies of liquids bonding achieved by weak, intermolecular interactions, considered as physical interactions. Then, a good wetting of a liquid metal on a solid substrate is usual to be observed. This is possible only if the interfacial bond is strong, i.e., chemical in nature. This condition, a strong interfacial and chemical in nature bond, is fulfilled for liquid metals on solid metals regardless of their miscibility, because, in this type of system, the interfacial bond is metallic [31-33].

\subsection{Diffusion}

In general, the concentration of an element diffusing within a solid from its surface is a function of both time $t$ and position $x$ (in one-dimensional problems). This one-dimensional non-steady-state case is described by the Fick's Second Law (Equation (2)):

$$
\frac{\partial C}{\partial T}=D \frac{\partial^{2} C}{\partial x^{2}}
$$

where $T$ is the temperature, $D$ corresponds to the diffusivity and $C$ represents the concentration of the diffusing element as function of time and position.

The solution to Equation (2) depends on the so-called initial conditions, describing the system. The boundary conditions, describing the hot-dip aluminizing, can be assumed as: at $t=0$, the aluminum concentration $C$ within the steel is equal to 0 , for every position $x$, comprised between 0 and infinity; and, for $t>0$, the aluminum concentration $C$ is equal to the surface concentration $C_{s}$ (fixed in time) in the position $x=0$ and it is equal to 0 in the position $x=\infty[34,35]$.

For the present case, the experimental setup for the hot-dip aluminizing process is sketched in Figure 2.

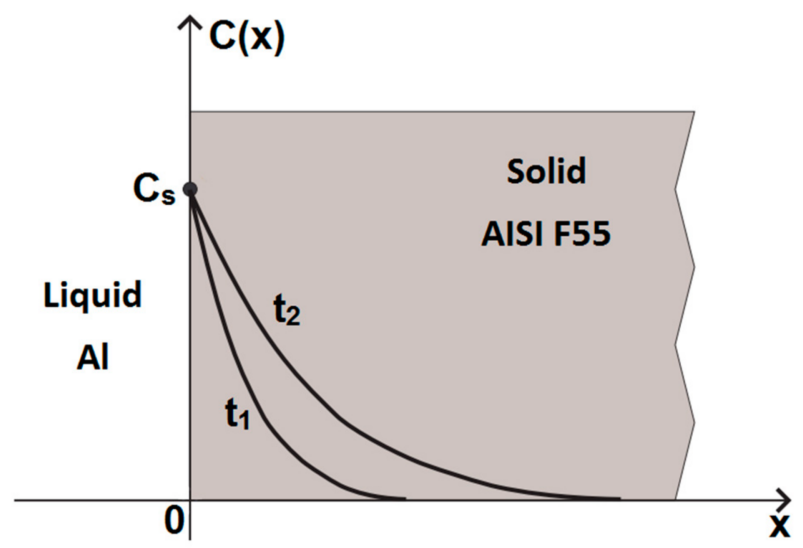

Figure 2. Schematic experimental setup for the hot-dip aluminizing process; the surface of the workpiece is at $x=0$ and extends to very large $x$; the aluminum concentration profile $C(x)$ evolves with time $t_{2}>t_{1}>0$.

\section{Results}

First, specimens drawn from a cold drawn bar have undergone hot-dip aluminizing trials at different temperatures to identify the optimal process temperature. These tests consisted in standard ASTM D7334-13 sessile drop tests. The results of these experiments are reported in Figure 3. Although the behavior is similar for most of the testing temperatures, it is possible to identify an optimal condition, processing the hot-dip aluminizing at $1100{ }^{\circ} \mathrm{C}$. 


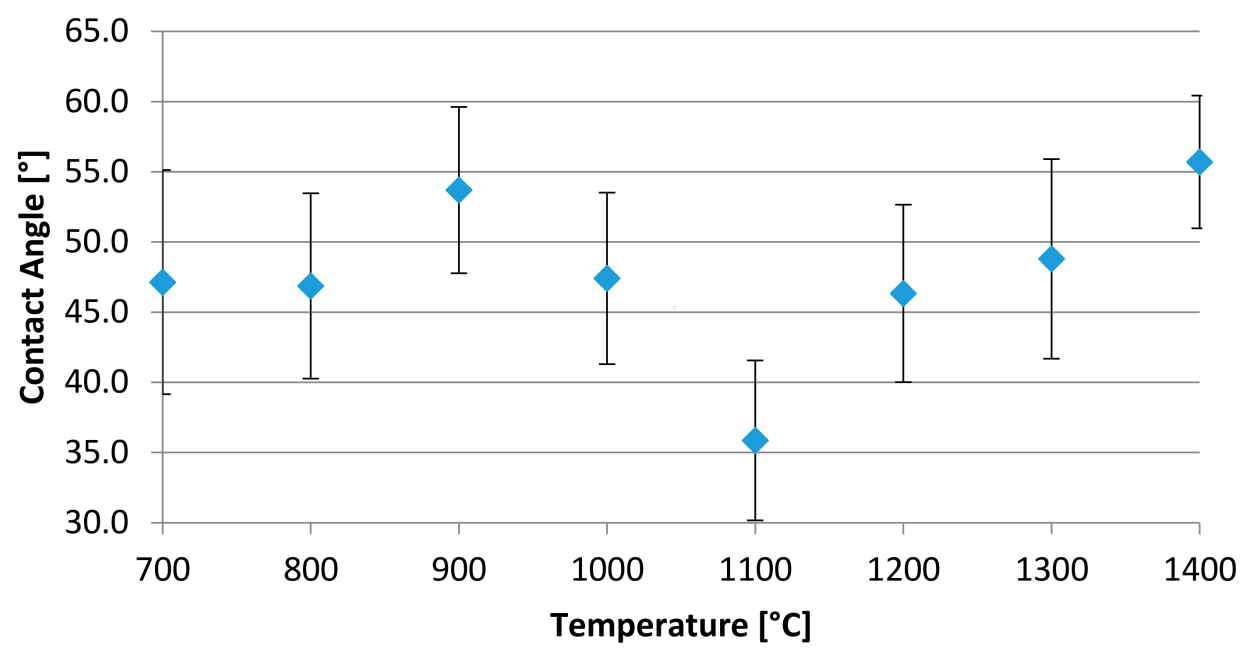

$\diamond$ Liquid Al / AISI F55

Figure 3. Sessile drop test describing the wettability by liquid aluminum of AISI F55 steel substrates, varying the temperature.

At this working temperature, the contact angle reaches a minimum, testifying a strong interaction between the liquid aluminum and the super duplex stainless steel substrate, which must involve a chemical bonding component [31].

Due to the above-mentioned results, the testing temperature for further hot-dip aluminizing trials has been chosen as $1100^{\circ} \mathrm{C}$.

Then, the investigation of the behavior of AISI F55 (UNS S32760) super duplex stainless steel, dealing with a thermo-chemical surface treatment, such as hot-dip aluminizing, has been performed. The data allow the identification and the understanding how microstructural features are affected by this process.

Optical microscopy highlights the complexity of the microstructure featuring this steel grade and its interaction with liquid aluminum. Both the thermal treatments and the mechanical deformation (cold rolling) drastically modify the microstructure. The commercial cold drawn samples display the typical "pancake" microstructure featuring cold worked duplex and super duplex stainless steels (Figure 4A). In the samples solubilized at $1400{ }^{\circ} \mathrm{C}$, the austenitic phase is present in lower volume fractions and surrounds the ferritic grains as allotriomorphs or it enters within the grains as Widmanstätten $\gamma$-austenite plates (Figure 4C). The solubilized at $1300{ }^{\circ} \mathrm{C}$ specimens reveal a microstructure, which is featured by roundish austenitic grains dispersed within the ferritic matrix (Figure 4B). In the annealed thermally treated samples, the secondary austenite precipitation has been trigged (Figure 4D) and it is followed by the precipitates competitive growth with the ongoing of the thermal treatment. At $210 \mathrm{~s} / \mathrm{mm}$ (Figure 4E), a static recovery of the ferritic grains is reported to occur and, then, the competitive coarsening of austenitic grains leads the microstructure evolution until $360 \mathrm{~s} / \mathrm{mm}$ (Figure 4F) of holding time [26,36]. Moreover, the effect of the deformation by the cold rolling can be detected, observing the distortion of the austenitic grains, which is more marked in the samples experiencing higher strains (Figure 4G,H). 

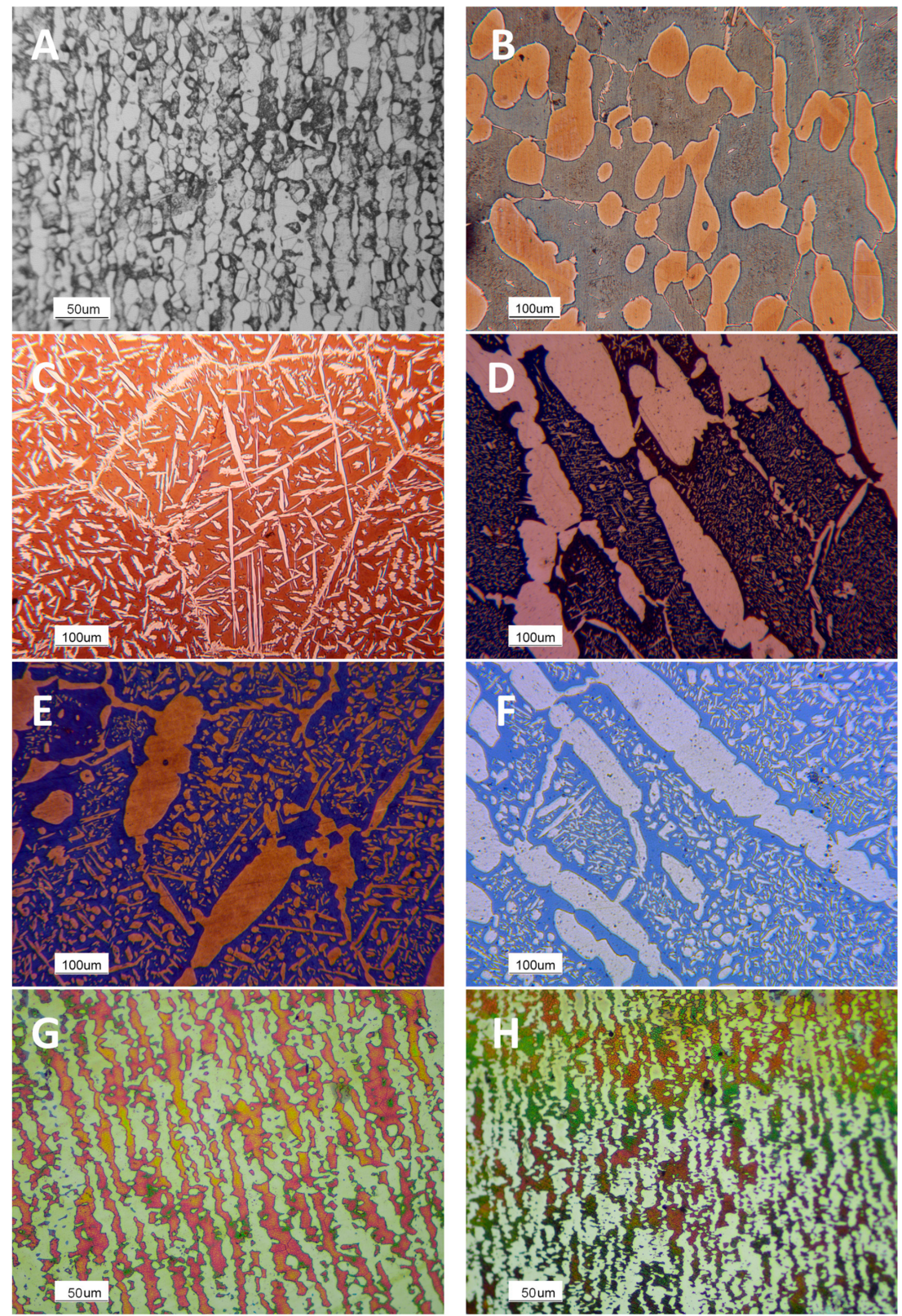

Figure 4. Samples microstructure through optical microscopy: the cold drawn reference specimen (A); the solution annealed at $1300{ }^{\circ} \mathrm{C}(\mathrm{B})$; the solution annealed at $1400{ }^{\circ} \mathrm{C}(\mathrm{C})$; the samples annealed at $1080{ }^{\circ} \mathrm{C}$ for: $72 \mathrm{~s} / \mathrm{mm}$ (D); $210 \mathrm{~s} / \mathrm{mm}(\mathbf{E})$; and $360 \mathrm{~s} / \mathrm{mm}$ (F); and the cold rolled samples with: $60 \%$ (G); and $90 \%(\mathbf{H})$ reduction ratio.

Focusing the attention at the specimens' surfaces, it is possible to observe at low magnifications the enrichment at the surface in ferrite volume fraction. This phenomenon is related to the diffusion of aluminum within the substrate. Indeed, the aluminum is a strong ferrite-stabilizer element; thus, it promotes the decrease of the austenitic phase content, even if present in very low percentages. The clear appearance of this fact allows the measurement of a surficial layer in which aluminum is diffused (Figure 5A). 

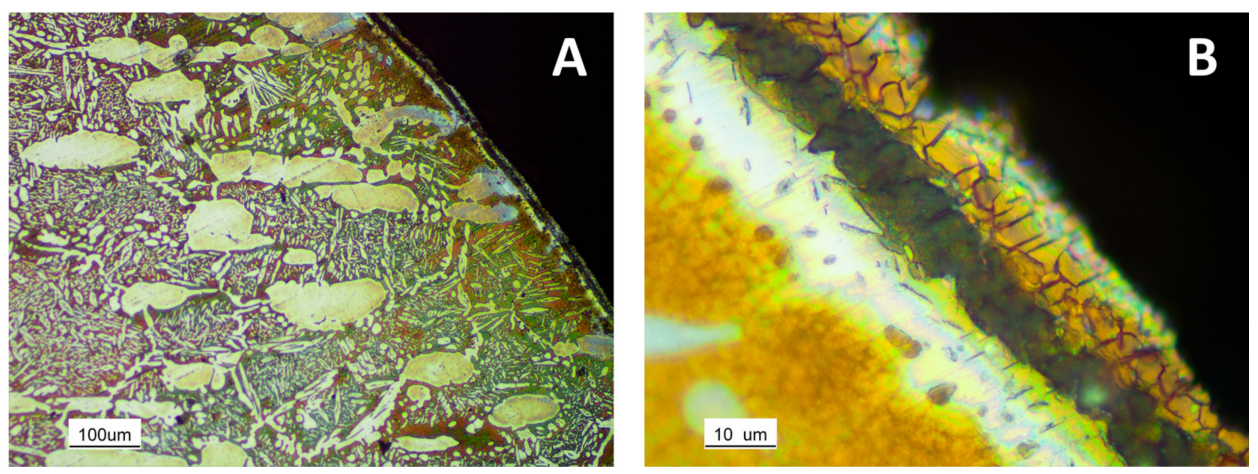

Figure 5. Ferrite-rich external layer given by aluminum diffusion (A); and surficial aluminum-rich layers and intermetallic precipitates (B) of the sample thermally annealed at $1080{ }^{\circ} \mathrm{C}$ for $360 \mathrm{~s} / \mathrm{mm}$ and hot-dip aluminized at $1100{ }^{\circ} \mathrm{C}$ for $2700 \mathrm{~s}$.

At higher magnifications, surficial layers composed of aluminum-rich alloyed steel and intermetallic compounds appear evident. The intermetallic precipitates, suggesting the different involved phases, displaying two different morphologies: one roundish and one acicular. Due to the too high extraction rate from the liquid aluminum, a thick aluminum external layer is not present (Figure 5B).

Through optical microscopy coupled with quantitative metallographic analysis, it is possible to obtain further important data. First, the austenite volume fraction, which is at the same time extremely important but very variable, can be measured. The results of this analysis are reported in Table 1.

Table 1. Austenite volume fraction.

\begin{tabular}{ccccccccc}
\hline Sample & CD & LS & HS & A72 & A210 & A360 & S1300 & S1400 \\
\hline $\begin{array}{c}\text { Austenite } \\
\text { (Vol. \%) }\end{array}$ & 55.3 & 49.2 & 54.6 & 47.7 & 45.9 & 53.7 & 31.8 & 37.3 \\
$\begin{array}{c}\text { Error } \\
\text { (Vol. \%) }\end{array}$ & 2.3 & 0.9 & 1.8 & 3.4 & 2.5 & 2.7 & 2.5 & 1.7 \\
\hline
\end{tabular}

Further data can be obtained measuring the other features highlighted by micrographic analysis of the hot-dip aluminized surfaces. In detail, the external layer enriched in the ferritic phase, generated by the increase of the local aluminum content via diffusion, has been estimated. Data are shown in Figure 6.

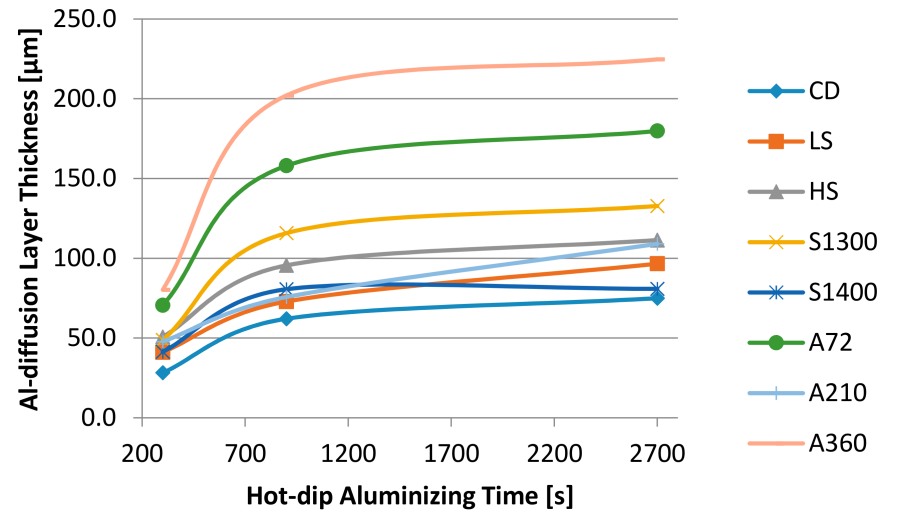

Figure 6. Ferrite-rich surficial layers thickness given by the aluminum diffusion within the tested alloy. 
Further, the thickness of the surficial aluminum-rich layers of the super duplex stainless steel substrates has been evaluated (Figure 5B). The collected results are displayed in Figure 7.

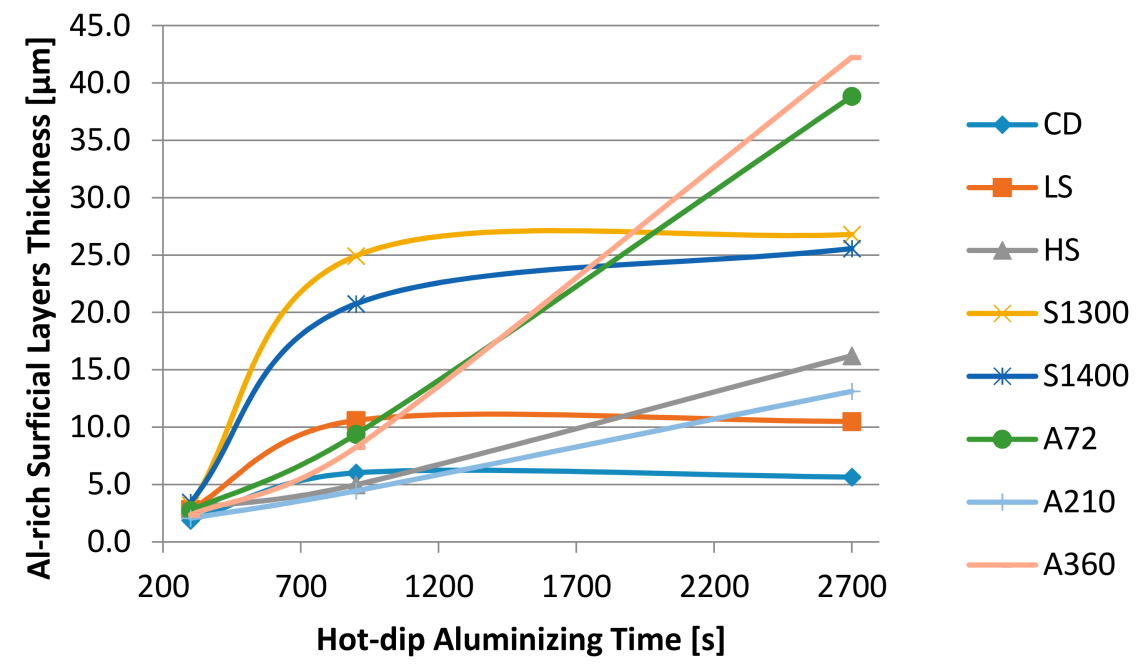

Figure 7. Thickness of the surficial aluminum-rich layers.

Finally, the thickness of the super duplex stainless steel substrates eroded by liquid aluminum during the hot-dip aluminizing process, as the distance from the projection of the initial surface and the final surface, has been measured. The results are reported in Figure 8.

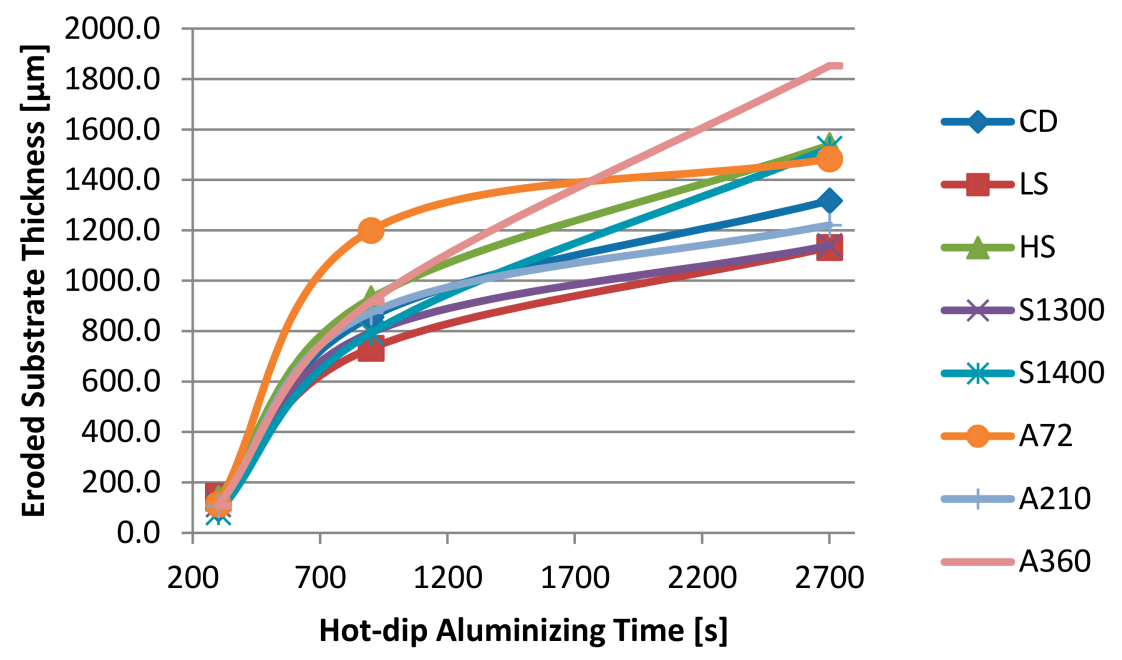

Figure 8. Thickness of the surficial layer of the steel substrate eroded by liquid aluminum.

In parallel, scanning electron microscope has been used, exploiting its different functions, to identify and describe the microstructural features individuated through optical microscopy. In Figure 9, the elemental maps of the surficial aluminum-diffusion layer in the sample thermally annealed for $360 \mathrm{~s} / \mathrm{mm}$ and aluminized for $2700 \mathrm{~s}$ has been reported. This sample has been chosen due to the thickness of its surficial aluminum-diffusion layer, which results maximized in comparison with other specimens. This elemental map shows how deep the aluminum diffusion proceeded and its interactions with the substrate alloy, which is chemically extremely complex. In the blue boxes the ferrite-stabilizer elements ( $\mathrm{Cr}, \mathrm{Mo}, \mathrm{Al}$ ) surficial enrichment has been highlighted. In the yellow boxes, the $\mathrm{Ni}$ variation related to the presence of austenitic precipitates has been underlined. 


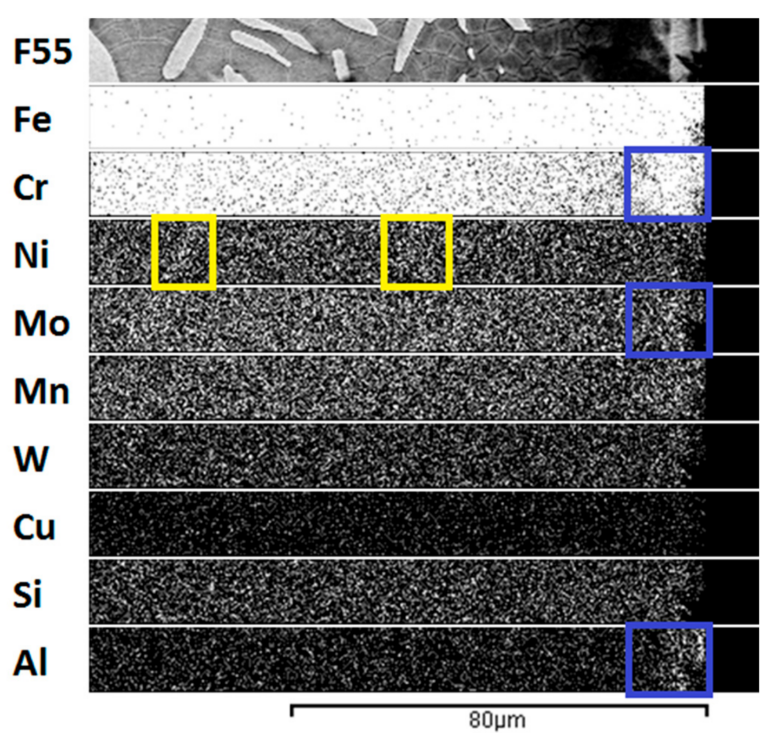

Figure 9. Scanning electron microscope dispersive X-ray microanalysis (SEM/EDS) elemental maps of the surficial aluminum-diffusion layer in the sample annealed at $1080{ }^{\circ} \mathrm{C}$ for $360 \mathrm{~s} / \mathrm{mm}$ and aluminized at $1100{ }^{\circ} \mathrm{C}$ for $2700 \mathrm{~s}$. Ferrite-stabilizer element $(\mathrm{Cr}, \mathrm{Mo}$, and $\mathrm{Al})$ surface variation is highlighted in the blue boxes, while austenite-former element $(\mathrm{Ni})$ variation, related to the presence of austenitic precipitates, has been underlined in the yellow boxes.

In Table 2 are shown data collected through SEM/EDS analysis, which regard the local chemical composition of the two constituent phases. Alloying elements redistribute themselves within ferrite or austenite preferentially. Their behavior is extremely important, driving the diffusion phenomena and the concurring in the chemical reactions intermetallic compounds.

Table 2. Local chemical composition (wt. \%) measured within austenitic and ferritic phases.

\begin{tabular}{lllllllll}
\hline Sample & Phase & Cr (\%) & $\begin{array}{l}\text { Mn } \\
\text { (\%) }\end{array}$ & Fe (\%) & Ni (\%) & Cu (\%) & Mo (\%) & W (\%) \\
& & & & & & & \\
\multirow{2}{*}{ D } & $\alpha$ & 27.01 & 0.44 & 60.46 & 5.91 & 0.55 & 4.74 & 0.89 \\
& $\gamma$ & 24.13 & 0.63 & 62.14 & 8.52 & 0.78 & 3.19 & 0.61 \\
\hline \multirow{2}{*}{ LS } & $\alpha$ & 26.79 & 0.51 & 60.56 & 5.22 & 0.67 & 5.14 & 1.11 \\
& $\gamma$ & 24.53 & 0.66 & 61.87 & 7.59 & 0.82 & 3.58 & 0.95 \\
\hline \multirow{2}{*}{ HS } & $\alpha$ & 26.21 & 0.58 & 60.45 & 6.03 & 0.72 & 4.97 & 1.04 \\
& $\gamma$ & 24.33 & 0.82 & 62.27 & 7.13 & 0.93 & 3.78 & 0.74 \\
\hline \multirow{2}{*}{ A72 } & $\alpha$ & 24.18 & 0.76 & 58.50 & 5.31 & 1.07 & 8.12 & 2.06 \\
& $\gamma$ & 22.87 & 0.77 & 60.10 & 9.05 & 1.11 & 4.28 & 1.82 \\
\hline \multirow{2}{*}{ A210 } & $\alpha$ & 26.60 & 0.65 & 58.61 & 4.80 & 0.54 & 7.15 & 1.65 \\
& $\gamma$ & 24.50 & 0.57 & 61.15 & 7.95 & 0.71 & 3.65 & 1.48 \\
\hline \multirow{2}{*}{ A360 } & $\alpha$ & 26.13 & 0.48 & 57.37 & 4.48 & 1.36 & 8.49 & 1.69 \\
& $\gamma$ & 24.76 & 0.32 & 61.75 & 7.71 & 0.53 & 3.52 & 1.42 \\
\hline \multirow{2}{*}{ S1300 } & $\alpha$ & 26.04 & 0.59 & 59.17 & 6.61 & 0.47 & 5.52 & 1.60 \\
& $\gamma$ & 24.21 & 0.98 & 61.22 & 7.85 & 1.36 & 3.03 & 1.36 \\
\hline \multirow{2}{*}{ S1400 } & $\alpha$ & 25.64 & 0.70 & 59.56 & 6.99 & 0.82 & 4.77 & 1.53 \\
& $\gamma$ & 24.38 & 0.88 & 61.19 & 7.41 & 0.81 & 3.89 & 1.44 \\
\hline
\end{tabular}

Special attention has been paid to the surficial aluminum-rich layers of the super duplex stainless steel substrates. The chemical analysis of ferritic phase has been performed as depth profile with 
a $50-\mu \mathrm{m}$ spacing. This allows the measurement of the aluminum content, testifying its diffusion kinetics (Figure 10 and Table 3).

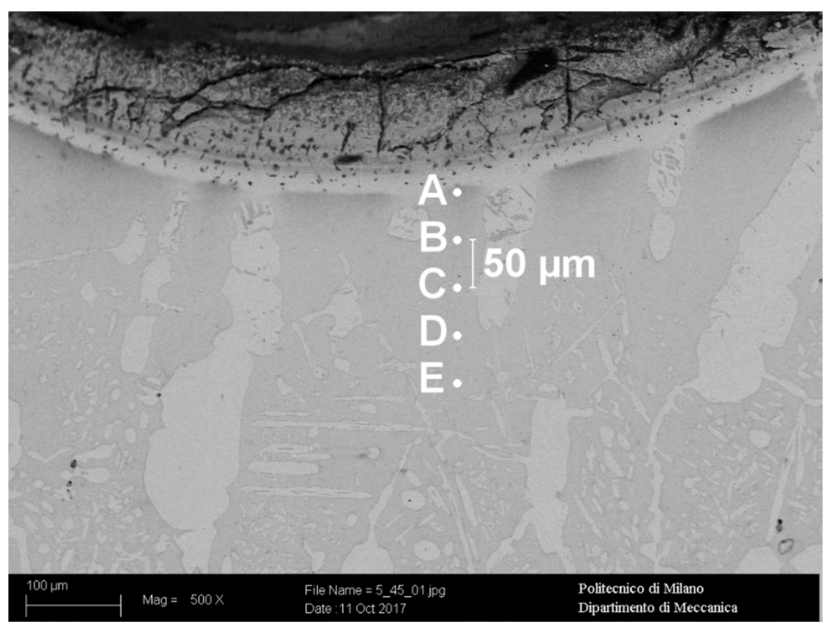

Figure 10. Scanning electron microscope secondary electron detector (SEM/SE) image of the surficial aluminum-rich layers of the sample annealed at $1080{ }^{\circ} \mathrm{C}$ for $360 \mathrm{~s} / \mathrm{mm}$ and aluminized at $1100{ }^{\circ} \mathrm{C}$ for $2700 \mathrm{~s}$.

Table 3. Chemical analysis depth profile with a 50- $\mu \mathrm{m}$ spacing, referring to the areas highlighted in Figure 10.

\begin{tabular}{cccccccccc}
\hline Depth & Al (\%) & Si (\%) & Cr (\%) & Mn (\%) & Fe (\%) & Ni (\%) & Cu (\%) & Mo (\%) & W (\%) \\
\hline A-0 $\mu \mathrm{m}$ & 0.63 & 0.57 & 23.12 & 0.48 & 61.88 & 7.18 & 0.52 & 4.38 & 1.23 \\
B-50 $\mu \mathrm{m}$ & 0.25 & 0.78 & 25.68 & 0.79 & 59.97 & 6.63 & 0.55 & 5.23 & 0.11 \\
C-100 $\mu \mathrm{m}$ & 0.12 & 0.68 & 24.92 & 0.89 & 60.97 & 6.93 & 0.46 & 4.27 & 0.76 \\
D-150 $\mu \mathrm{m}$ & 0.07 & 0.54 & 24.64 & 0.77 & 61.28 & 6.43 & 0.89 & 4.59 & 0.79 \\
E-200 $\mu \mathrm{m}$ & - & 0.54 & 25.86 & 0.63 & 59.44 & 6.47 & 0.89 & 5.03 & 1.14 \\
\hline
\end{tabular}

Further, SEM/EDS allows the chemical characterization of the intermetallic precipitates, highlighting the differences in composition of the phases (Figure 11 and Table 4). Since they are not stoichiometric (the alloying metallic atoms could be $\mathrm{Me}=\mathrm{Fe}, \mathrm{Cr}$, etc.), the intermetallic phase may be identified by aluminum atomic percentage [37-39].

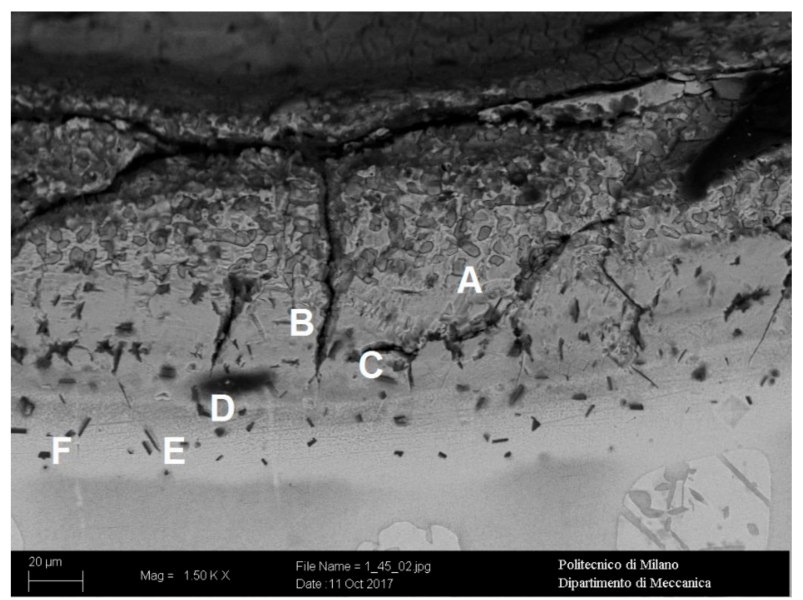

Figure 11. SEM/SE image of the surficial aluminum-rich layers and the intermetallic compounds precipitates with of the sample annealed at $1080{ }^{\circ} \mathrm{C}$ for $72 \mathrm{~s} / \mathrm{mm}$ and aluminized at $1100{ }^{\circ} \mathrm{C}$ for $2700 \mathrm{~s}$. 
Table 4. Chemical composition (at. \%) measured through SEM/EDS in the marked areas, highlighted in Figure 11, of the sample annealed at $1080{ }^{\circ} \mathrm{C}$ for $72 \mathrm{~s} / \mathrm{mm}$ and aluminized at $1100{ }^{\circ} \mathrm{C}$ for $2700 \mathrm{~s}$.

\begin{tabular}{ccccccccccc}
\hline $\begin{array}{c}\text { Analyzed } \\
\text { Area }\end{array}$ & $\begin{array}{c}\text { Al } \\
\text { (at. \%) }\end{array}$ & $\begin{array}{c}\text { Si } \\
\text { (at. \%) }\end{array}$ & $\begin{array}{c}\text { Cr } \\
\text { (at. \%) }\end{array}$ & $\begin{array}{c}\text { Mn } \\
\text { (at. \%) }\end{array}$ & $\begin{array}{c}\text { Fe } \\
\text { (at. \%) }\end{array}$ & $\begin{array}{c}\text { Ni } \\
\text { (at. \%) }\end{array}$ & $\begin{array}{c}\text { Cu } \\
\text { (at. \%) }\end{array}$ & $\begin{array}{c}\text { Mo } \\
\text { (at. \%) }\end{array}$ & $\begin{array}{c}\text { W } \\
\text { (at. \%) }\end{array}$ & $\begin{array}{c}\text { Intermetallic } \\
\text { Phase }\end{array}$ \\
\hline A & 27.23 & 1.36 & 9.07 & 0.41 & 57.62 & 2.69 & - & 1.38 & 0.24 & $\mathrm{Al}^{-\mathrm{Me}_{3}}$ \\
B & 33.90 & 2.70 & 10.36 & 0.06 & 29.74 & 12.92 & 1.81 & 8.41 & 0.10 & $\mathrm{Al}_{2}-\mathrm{Me}_{2}$ \\
C & 53.30 & 2.70 & 13.19 & 0.39 & 26.05 & 2.56 & 0.15 & 1.39 & 0.28 & $\mathrm{Al}-\mathrm{Me}$ \\
D & 88.23 & 0.14 & 4.37 & - & 6.44 & 0.46 & - & 0.27 & 0.09 & $\mathrm{Al}-\mathrm{Me}$ \\
E & 78.04 & 1.07 & 6.60 & 0.21 & 12.05 & 1.20 & 0.25 & 0.50 & 0.07 & $\mathrm{Al}-\mathrm{Me}$ \\
F & 86.48 & 0.15 & 4.37 & 0.03 & 7.70 & 0.51 & 0.23 & 0.44 & 0.09 & $\mathrm{Al}-\mathrm{Me}$ \\
\hline
\end{tabular}

Finally, a SEM/EBSD map has been collected at the surficial aluminum-rich layers of the super duplex stainless steel substrates of the sample annealed at $1080^{\circ} \mathrm{C}$ for $360 \mathrm{~s} / \mathrm{mm}$ and aluminized at $1100{ }^{\circ} \mathrm{C}$ for $2700 \mathrm{~s}$, to identify and quantify through diffraction the constituent phases. The gathered data are displayed in Figure 12. Due to the complexity of the chemical system, the detected phases are considered as random substitutional solid solutions, with separate chemical and magnetic contributions to the excess Gibbs energy. This means that, in lattices, atoms may be replaced by other different elements, without changing the lattice structure of the phase. Thus, thanks to the literature, phases may be grouped by the lattice system in the following list: $\alpha$-Fe (b.c.c.), $\gamma$-Fe (f.c.c.), $\mathrm{Cr}_{5} \mathrm{Al}_{8}$ (b.c.c.), $\mathrm{Fe}_{2} \mathrm{Al}_{5}$ (orthorhombic), $\mathrm{Al}_{3} \mathrm{Ni}_{2}$ (h.c.p.), and $\mathrm{FeAl}_{3}$ (monoclinic).

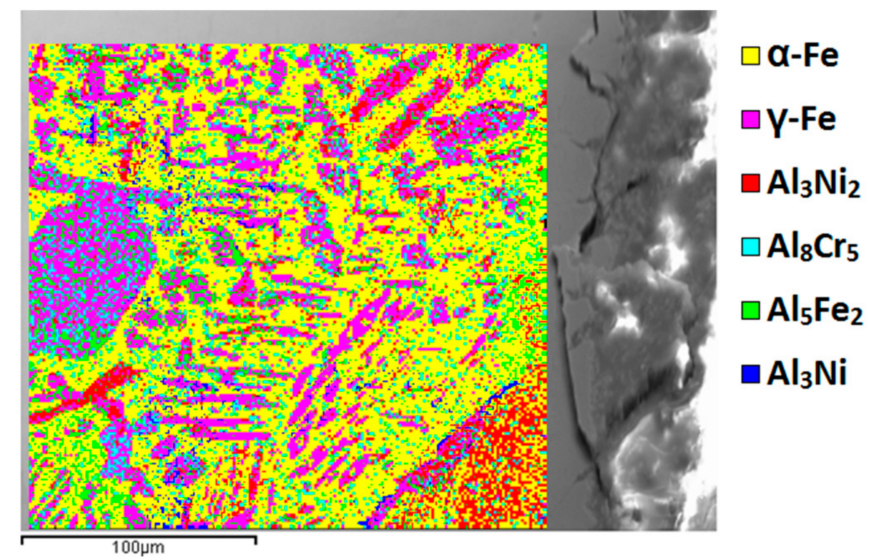

Figure 12. Scanning electron microscope electron backscattered diffraction mapping (SEM/EBSD) of the surficial aluminum-rich layers of the sample annealed at $1080{ }^{\circ} \mathrm{C}$ for $360 \mathrm{~s} / \mathrm{mm}$ and aluminized at $1100{ }^{\circ} \mathrm{C}$ for $2700 \mathrm{~s}$.

\section{Discussion}

The sessile drop tests identify $1100{ }^{\circ} \mathrm{C}$ as optimal processing temperature for the hot-dip aluminizing. This result is in accordance with the forecasts. Taking into account the influence of temperature on diffusion [35], chemical reactions kinetics and liquid viscosity [40], higher temperatures correspond to a higher ability of liquid aluminum to react with the super duplex stainless steel substrates. On the other hand, this effect is balanced by the melting tendency of aluminum-rich intermetallic compounds, which are generated by the interaction of aluminum with the investigated alloy. This second feature is described by phase diagrams (Figure 13) for systems similar to the tested alloy and the limiting melting temperature for aluminum-rich intermetallic can be identified at $1160{ }^{\circ} \mathrm{C}[37-39,41-43]$. 


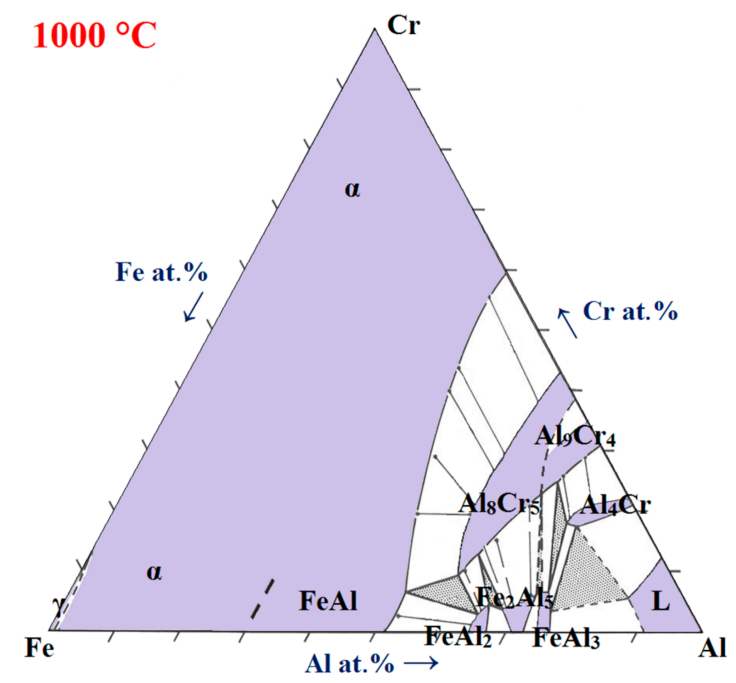

Figure 13. Isothermal section of the Fe-Al-Cr system at $1000^{\circ} \mathrm{C}$. The phase boundary between a-(Fe, $\left.\mathrm{Al}\right)$ and $\mathrm{FeAl}$ has not been determined and is therefore given by a broken line.

At $1100{ }^{\circ} \mathrm{C}$ working temperature, the contact angle tests display a strong interaction between the liquid aluminum and the super duplex stainless steel substrate, involving a chemical contribution [31,44]. This can be observed also via optical microscopy, which highlight the presence of intermetallic compounds at the solid-liquid interface, formed by the diffusing aluminum within the steel substrates, as displayed in Figure 5B. The thickness of this layer is the result of the kinetics intermetallic formation reactions as well as the result of the difference in kinetics between steel dissolution by liquid aluminum and the aluminum diffusion.

In detail, the aluminum diffuses in the external layers preferentially within ferritic phase with a diffusion rate two orders of magnitude higher than in austenite [45]. Further, aluminum acts as strong ferrite-stabilizer element, promoting the austenite to ferrite phase transformation and drastically increasing the local ferrite volume fraction [46]. Thus, the collected data prove the complete irrelevance of austenite content and morphology on the hot-dip aluminizing. Considering this, the role of ferritic phase features should be investigated deeply to achieve a complete description of the phenomena involved in hot-dip aluminizing.

Through these considerations, the different thicknesses reached by the surficial aluminum diffusion layer (Figure 6) can be related to different features characterizing the ferritic phase.

First, the minimum value reached by the thickness of the surficial aluminum diffusion layer developed on the commercial cold drawn SDSS sample should be underlined. This is connected to the extremely compact microstructure, reached through the forming processes, in which the lattice defects have been minimized.

It has been evaluated the influence of cold working, showing the slight influence of lattice defects generation on aluminum diffusion within the ferritic phase. Indeed, ferritic phase is less involved in deformation processes imposed by cold working, which are mainly concentrated within the austenitic phase, as described by micromechanics [47-51]. In addition, observing the collected data, as expected, the aluminum diffusion rate increases with the strain imposed by cold working.

In addition, the increase of the solution temperature leads to the slight enlargement of the surficial aluminum diffusion layer. This behavior is linked to the lattice defects thermally generated. However, the ferritic grain dimension also plays a major role, much smaller after the $1300{ }^{\circ} \mathrm{C}$ solution thermal treatment. Indeed, the presence of grain boundaries acts as short-circuit diffusion path, enhancing the aluminum diffusion in the ferritic phase [35].

The most interesting results are those obtained through the annealing thermal treatment, which reach an extremely large thickness of the surficial aluminum diffusion layer. In addition, in these cases, 
the same features of the solution thermal treated samples are involved. In detail, the extremely high influence given by grain boundaries can be pointed out as the responsible for such high diffusion rates of aluminum, since their presence has been multiplied by secondary austenite precipitation within ferritic matrix. The thermal generation of lattice defects can be observed in the maximum value of the aluminum diffusion rate associated to the maximum value of soaking time of the annealing thermal treatment [35,52]. The sample annealed for $210 \mathrm{~s} / \mathrm{mm}$ undergoes a static recovery phenomenon of the ferritic grains, decreasing the number of its internal $\delta / \delta$ boundaries and defects; then, also the aluminum diffusion rate is strongly reduced [26,36].

The same trends have been observed also regarding the thickness of the aluminum-rich interface (Figure 7). The minimum value is obtained by the commercial SDSS and is slightly improved by strain increase or by solution treatment temperature increase. The annealing treatment achieves again the best results, to increase the interfacial layer thickness. This confirms the main mechanisms acting on aluminum diffusion, which have been previously individuated and discussed.

Regarding the erosion of the SDSS substrate (Figure 8), the behavior of all samples is quite similar with the exception of the specimen annealed for $360 \mathrm{~s} / \mathrm{mm}$. This behavior highlights the importance of the short-circuit diffusion paths in this process. Indeed, the dissolution process is known to be controlled by diffusion and preferential leaching of $\mathrm{Ni}$, and in a second step of $\mathrm{Cr}$, migrating towards the surface of the material and segregating in sites where a minute amount of oxygen is present. The dissolution of the iron matrix occurs only after $\mathrm{Ni}$ and $\mathrm{Cr}$ are sufficiently depleted [53,54]. It can also be appreciated that the sample annealed for $360 \mathrm{~s} / \mathrm{mm}$ possesses one of the poorest content of $\mathrm{Ni}$ and $\mathrm{Cr}$ within the ferritic phase (Table 5), testifying the key role of these alloying elements in these liquid metal erosion/corrosion phenomena.

Table 5. Sum of Nickel and Chromium contents (wt. \%), key elements in the liquid metal erosion/corrosion phenomena between liquid aluminum and solid steel.

\begin{tabular}{lccccccccc}
\hline $\begin{array}{l}\text { Alloying } \\
\begin{array}{l}\text { Elements } \\
\text { Content }\end{array}\end{array}$ & Phase & CD & LS & HS & A72 & A210 & A360 & S1300 & S1400 \\
\hline $\begin{array}{l}\mathrm{Ni}+\mathrm{Cr} \\
\text { (wt. \%) }\end{array}$ & $\alpha$ & 32.92 & 32.01 & 32.24 & 29.49 & 31.4 & 30.61 & 32.65 & 32.63 \\
\hline
\end{tabular}

The combination of all of the effects comprehensive of all of the contributions can be plotted, as reported in Figure 14. From the data previously exposed, it can be observed that the major contribution is given by the eroded material from the SDSS substrate.

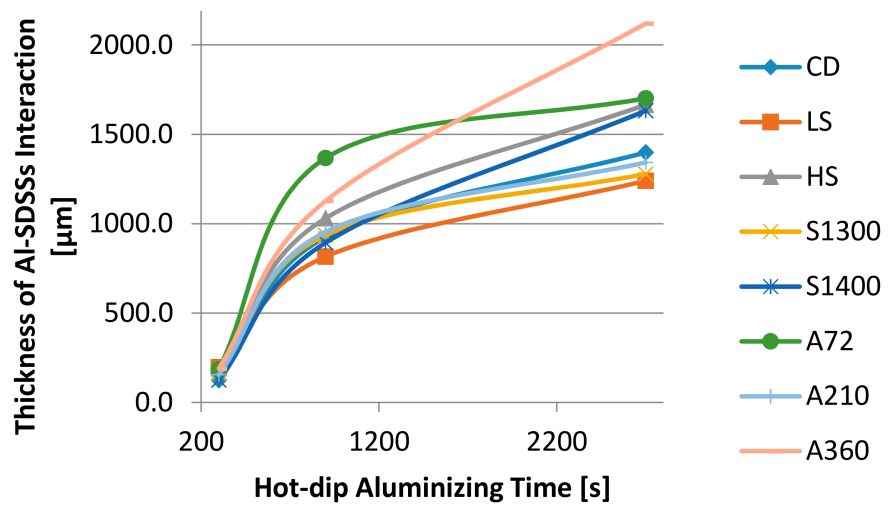

Figure 14. Combination of the thickness of the steel substrate eroded by liquid aluminum and the thickness of ferrite-rich surficial layers resulting by the aluminum diffusion.

The diffusion phenomena involved in hot-dip aluminizing have been highlighted by SEM analysis. SEM/EDS depth profile shows the diffusion of aluminum in the SDSS substrate, resulting in a good 
accordance with the data obtained through optical microscopy analysis (around 150-200 $\mu \mathrm{m}$ for the sample annealed for $360 \mathrm{~s} / \mathrm{mm}$ and aluminized for $2700 \mathrm{~s}$; Figure 5A, Figure 10 and Table 3). Further, it allows the identification of the intermetallic compounds generated at the interface between the SDSS substrate and the aluminum external layer as: $\mathrm{Al}-\mathrm{Me}_{3}, \mathrm{Al}-\mathrm{Me}_{2}, \mathrm{Al}-\mathrm{Me}, \mathrm{Al} 7-\mathrm{Me}, \mathrm{Al}_{3}-\mathrm{Me}$ (Figure 11 and Table 3). The detected phases also display the same morphology of those identified in the literature $[11,55,56]$.

SEM/EBSD detects phases as random substitutional solid solutions, due to the chemical complexity of the system. However, the Al diffusion can be observed through the phases maps. The distribution of the Al-rich phases (Figure 15), such as $\mathrm{Fe}_{2} \mathrm{Al}_{5}$ (orthorhombic) and $\mathrm{Al}_{3} \mathrm{Ni}_{\text {, is }}$ concentrated near the surface. On the other hand, Al-poor phases, such as $\mathrm{Cr}_{5} \mathrm{Al}_{8}$ (b.c.c.) and $\mathrm{Al}_{3} \mathrm{Ni}_{2}$ (h.c.p.), are mainly located in the innermost layers of the SDSS substrate, testifying the occurrence of the diffusion phenomena in hot-dip aluminizing. Further, comparing the $\mathrm{Al}_{3} \mathrm{Ni}$ and $\alpha$-Fe (b.c.c.) phases maps, the location of this Al-rich phase linked to the $\alpha$-Fe (b.c.c.) grain boundaries should be underlined. This demonstrates the major role played by the short-circuit diffusion paths in this process [35].

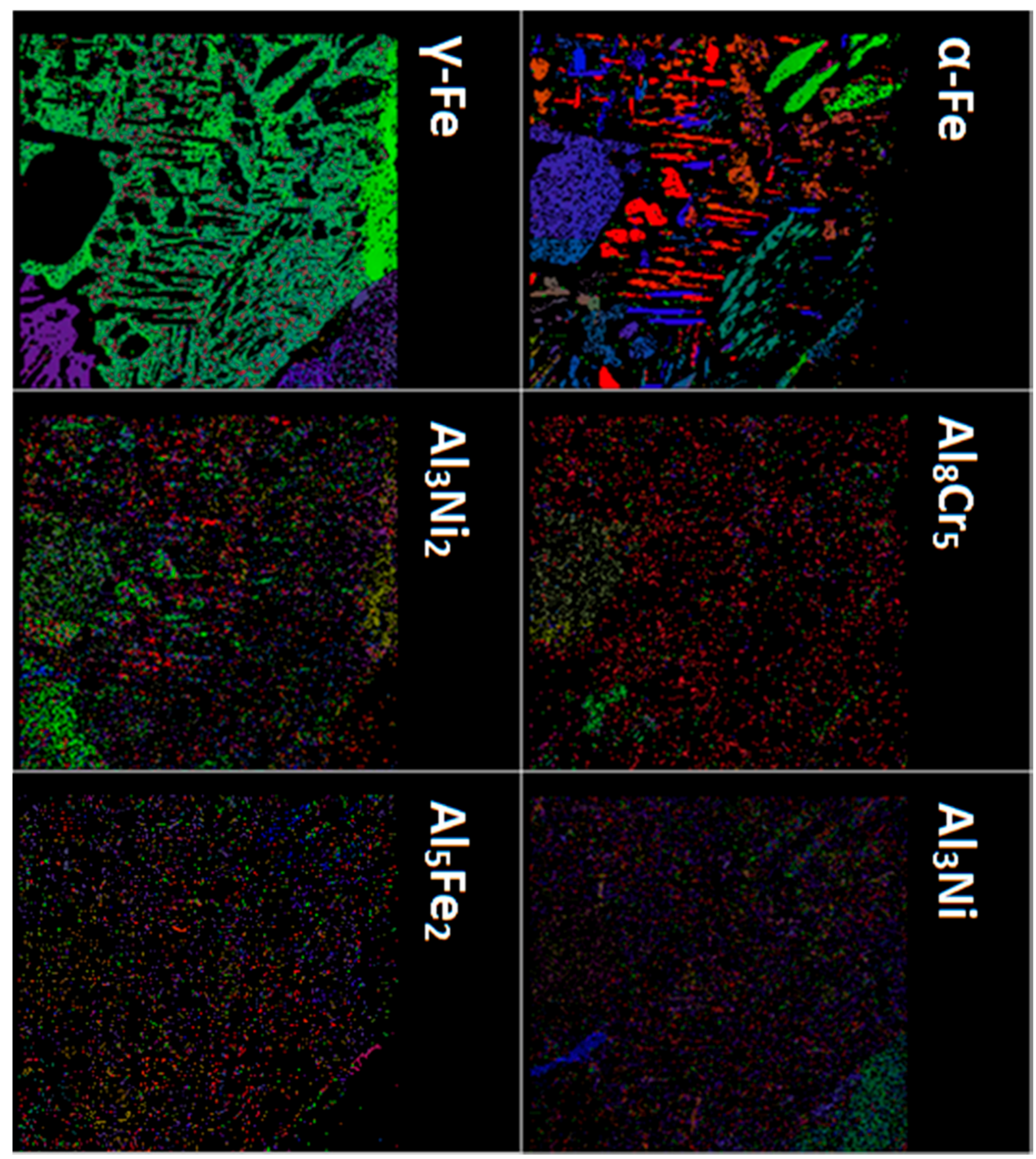

Figure 15. Phases maps obtained through SEM/EBSD measurement reported in Figure 12.

\section{Conclusions}

This study has investigated the behavior of super duplex stainless steels in hot-dip aluminizing process. The $1100{ }^{\circ} \mathrm{C}$ treatment temperature has been individuated as the best working condition 
through sessile drop tests, displaying the occurrence of a strong chemical interaction. This is also demonstrated by the generation of intermetallic compounds at the interface.

During hot-dip aluminizing process, aluminum diffuses preferentially within ferritic phase with a diffusion rate two orders of magnitude higher than in austenite and acts as strong ferrite-stabilizer element, increasing the local ferrite volume fraction. Thus, the hot-dip aluminizing process relies totally on ferritic phase and its features.

Cold working increases aluminum diffusivity but slightly, since the strains are mainly concentrated within the austenite.

The thermal annealing at $1080{ }^{\circ} \mathrm{C}$ for $360 \mathrm{~s} / \mathrm{mm}$ after a solution thermal treatment at $1300{ }^{\circ} \mathrm{C}$ for $60 \mathrm{~s} / \mathrm{mm}$ results as the best SDSS substrate starting condition to increase the interfacial layer thickness. The higher diffusivity of aluminum results due to thermal generation of lattice defects and the influence given by grain boundaries, which have been multiplied by secondary austenite precipitation within ferritic matrix, acting as short-circuit diffusion paths. In addition, the chemical composition of the ferritic matrix, specifically the $\mathrm{Ni}$ and $\mathrm{Cr}$ content, plays a role but it is less significant.

Author Contributions: Andrea Francesco Ciuffini conceived and designed the experiments, performed the experiments, analyzed the data and wrote the paper. Silvia Barella conceived and designed the experiments and reviewed the paper. Cosmo Di Cecca performed the experiments and analyzed the data. Andrea Gruttadauria conceived and designed the experiments and reviewed the paper. Davide Mombelli designed the experiments. Carlo Mapelli contributed reagents/materials/analysis tools and review the paper.

Conflicts of Interest: The authors declare no conflicts of interest.

\section{References}

1. Żaba, K. Wear Resistance of Aluminized Steel Plates. Arch. Metall. Mater. 2011, 56. [CrossRef]

2. Heo, N.H.; Kim, M.T.; Shin, J.H.; Kim, C.Y. Simultaneous chromizing and aluminizing using chromium oxide and aluminum: (II) on austenitic stainless steel. Surf. Coat. Technol. 2000, 124, 39-43. [CrossRef]

3. Sharafi, S.; Farhang, M.R. Effect of aluminizing on surface microstructure of an HH309 stainless steel. Surf. Coat. Technol. 2006, 200, 5048-5051. [CrossRef]

4. Messaoudi, K.; Huntz, A.M.; Lesage, B. Diffusion and growth mechanism of $\mathrm{Al}_{2} \mathrm{O}_{3}$ scales on ferritic $\mathrm{Fe}-\mathrm{Cr}-\mathrm{Al}$ alloys. Mater. Sci. Eng. A 1998, 247, 248-262. [CrossRef]

5. Sadique, S.E.; Mollah, M.A.H.; Ali, M.M.; Haque, M.M.; Basri, S.; Ahmad, M.M.H.M.; Sapuan, S.M. Influence of Aluminium Additions on the Rate of Oxidation of Iron-Chromium Alloys. J. Corros. Sci. Eng. 2000, 1, 18.

6. Badini, C.; Laurella, F. Oxidation of FeCrAl alloy: Influence of temperature and atmosphere on scale growth rate and mechanism. Surf. Coat. Technol. 2001, 135, 291-298. [CrossRef]

7. Perujo, A.; Forcey, K.S. Tritium permeation barriers for fusion technology. Fusion Eng. Des. 1995, $28,252-257$. [CrossRef]

8. Kalin, B.A.; Yakushin, V.L.; Fomina, E.P. Tritium barrier development for austenitic stainless steel by its aluminizing in a lithium melt. Fusion Eng. Des. 1998, 41, 119-127. [CrossRef]

9. Hollenberg, G.W.; Simonen, E.P.; Kalinin, G.; Terlain, A. Tritium/hydrogen barrier development. Fusion Eng. Des. 1995, 28, 190-208. [CrossRef]

10. Benamati, G.; Chabrol, C.; Perujo, A.; Rigal, E.; Glasbrenner, H. Development of tritium permeation barriers on Al base in Europe. J. Nucl. Mater. 1999, 271-272, 391-395. [CrossRef]

11. Wang, D.Q. Phase evolution of an aluminized steel by oxidation treatment. Appl. Surf. Sci. 2008, 254, 3026-3032. [CrossRef]

12. Josh, D.L.; Easton, D.S.; Liu, C.T.; Babu, S.S.; David, S.A. Processing of $\mathrm{Fe}_{3} \mathrm{Al}$ and FeAl alloys by reaction synthesis. Intermetallics 1995, 3, 467-481.

13. Lauwerens, W.; De Boeck, A.; Thijs, M.; Claessens, S.; Van Stappen, M.; Steenackers, P. PVD Al-Ti and Al-Mn coatings for high temperature corrosion protection of sheet steel. Surf. Coat. Technol. 2001, 146-147, 27-32. [CrossRef]

14. Lee, P.-Y.; Chiu, L.-H.; Yang, C.-F.; Chen, W.-D.; Kai, W.; Chu, J.P. Improvement of environmental degradation resistance of Fe-Al-based alloys by surface modification treatments. Mater. Sci. Eng. A 1997, 239-240, 736-740. [CrossRef] 
15. Su, C.W.; Lee, J.W.; Wang, C.S.; Chao, C.G.; Liu, T.F. The effect of hot-dipped aluminum coatings on Fe-8Al-30Mn-0.8C alloy. Surf. Coat. Technol. 2008, 202, 1847-1852. [CrossRef]

16. Li, Y.J.; Zhang, Y.L.; Liou, Y.X. Characteristics of phase constitution in the Fe-Al alloy layer of calorized steel pipe. J. Mater. Sci. 1995, 30, 2635-2639. [CrossRef]

17. Wang, D.; Shi, Z.; Zou, L. A liquid aluminum corrosion resistance surface on steel substrate. Appl. Surf. Sci. 2003, 214, 304-311. [CrossRef]

18. Young, G.A.; Wilkening, W.W.; Morton, D.S.; Richey, E.; Lewis, N. Assessment of lean grade duplex stainless steels for nuclear power applications. In Proceedings of the 15th International Conference on Environmental Degradation of Materials in Nuclear Power Systems -Water Reactors-2011, Colorado Springs, CO, USA, 7-11 August 2011; The Minerals, Metals \& Materials Society: Pittsburgh, PA, USA.

19. Wang, Y.Q.; Yang, B.; Han, J.; Dong, F.; Wang, Y.L. Localized Corrosion of Thermally Aged Cast Duplex Stainless Steel for Primary Coolant Pipes of Nuclear Power Plant. Procedia Eng. 2012, 36, 88-95. [CrossRef]

20. Gunn, R.N. Duplex Stainless Steels, 1st ed.; Woodhead Publishing: Sawston, Cambridge, UK, 1997; pp. 1-12.

21. Mateo, A.; Girone, A.; Keichel, J.; Llanes, L.; Akdut, N.; Anglada, M. Cyclic deformation behaviour of superduplex stainless steels. Mater. Sci. Eng. A 2001, 314, 176-185. [CrossRef]

22. Ciuffini, A.; Barella, S.; Di Cecca, C.; Gruttadauria, A.; Crugnola, S.; Mapelli, C. Local pitting corrosion resistance evaluation in large forged UNS-S32760 super duplex stainless steel parts of a sphere valve for the oil \& gas industry. Metall. Ital. 2017, 10, 33-45.

23. Charles, J. 10 years later, Obviously duplex grades in industrial applications look like a success story. In Proceedings of the 6th World Duplex Conference, Venice, Italy, 2000; AIM: Milan, Italy.

24. Johansson, K. Duplex stainless steels: Past, present and future. In Proceedings of the 6th World Duplex Conference, Venice, Italy, 2000; AIM: Milan, Italy.

25. Nilsson, J.O. Super duplex stainless steels. Mater. Sci. Technol. 1992, 8, 685-700. [CrossRef]

26. Ciuffini, A.; Barella, S.; Di Cecca, C.; Gruttadauria, A.; Mapelli, C.; Mombelli, D. Isothermal Austenite-Ferrite Phase Transformations and Microstructural Evolution during Annealing in Super Duplex Stainless Steels. Metals 2017, 7, 368. [CrossRef]

27. Southwick, P.D.; Honeycombe, R.W.K. Decomposition of ferrite to austenite in $26 \% \mathrm{Cr}-5 \% \mathrm{Ni}$ stainless steel. Met. Sci. 1980, 7, 253-261. [CrossRef]

28. Hsieh, C.-C.; Wu, W. Precipitation of Phase Using General Diffusion Equation with Comparison to Vitek Diffusion Model in Dissimilar Stainless Steels. J. Metall. 2012, 2012, 1-7. [CrossRef]

29. Jackson, E.M.L.E.M.; Visser, P.E.; Cdornish, L.A. Distinguishing between Chi and Sigma phases in duplex stainless steels using potentiostatic etching. Mater. Charact. 1993, 31, 185-190. [CrossRef]

30. Miranda, M.A.R.; Sasaki, J.M.; Tavares, S.S.M.; De Abreu, H.F.G.; Neto, J.M. The use of X-ray diffraction, microscopy, and magnetic measurements for analysing microstructural features of a duplex stainless steel. Mater. Charact. 2005, 54, 387-393. [CrossRef]

31. Champion, J.A.; Keene, B.J.; Sillwood, J.M. Wetting of aluminium oxide by molten aluminium and other metals. J. Mater. Sci. 1969, 4, 39-49. [CrossRef]

32. Hashim, J.; Looney, L.; Hashmi, M.S.J. The wettability of SiC particles by molten aluminium alloy. J. Mater. Process. Technol. 2001, 119, 324-328. [CrossRef]

33. Bracco, G.; Holst, B. Surface Science Techniques, 1st ed.; Springer-Verlag Berlin Heidelberg: Berlin, Germany, 2013; pp. 3-34.

34. Lam, H.S. Multicomponent diffusion revisited. Phys. Fluids 2006, 18, 1-8. [CrossRef]

35. Baluffi, R.W.; Allen, S.M.; Carter, W.C. Kinetics of materials, 1st ed.; John Wiley \& Sons, Inc.: Hoboken, NJ, USA, 2005; pp. 77-98.

36. Alvarez-Armas, I.; Degallaix-Moreuil, S. Duplex Stainless Steels, 1st ed.; John Wiley \& Sons, Inc.: Hoboken, NJ, USA, 2009; pp. 115-140.

37. Murray, J.L. The Al-Cr (aluminum-chromium) system. J. Phase Equilib. 1998, 19, 367-375. [CrossRef]

38. Li, X.; Scherf, A.; Heilmaier, M.; Stein, F. The Al-Rich Part of the Fe-Al Phase Diagram. J. Phase Equilibria Diffus. 2016, 37, 162-173. [CrossRef]

39. Kuentzler, R. Ordering effects in the Fe-Al system. J. Phys. 1983, 44, 1167-1178. [CrossRef]

40. Ghatee, M.H.; Zare, M.; Zolghadr, A.R.; Moosavi, F. Temperature dependence of viscosity and relation with the surface tension of ionic liquids. Fluid Phase Equilib. 2010, 291, 188-194. [CrossRef] 
41. Huang, W.; Chang, Y.A. Thermodynamic properties of the Ni-Al-Cr system. Intermetallics 1999, 7, 863-874. [CrossRef]

42. Palm, M. Concepts derived from phase diagram studies for the strengthening of Fe-Al-based alloys. Intermetallics 2005, 13, 1286-1295. [CrossRef]

43. Palm, M. The Al-C-Fe syste-Phases and phase equilibria in the Al-rich corner. J. Alloys Compd. 1997, 252, 192-200. [CrossRef]

44. Eustathopoulos, N. Wetting by Liquid Metals-Application in Materials Processing: The Contribution of the Grenoble Group. Metals 2015, 5, 350-370. [CrossRef]

45. Oikawa, H. Review on lattice diffusion of substitutional impurities in iron. A summary report. Technol. Rep. Tohoku Univ. 1982, 47, 215-224.

46. Ennis, B.L.; Jimenez-Melero, E.; Mostert, R.; Santillana, B.; Lee, P.D. The role of aluminium in chemical and phase segregation in a TRIP-assisted dual phase steel. Acta Mater. 2016, 115, 132-142. [CrossRef]

47. Baczmański, A.; Braham, C. Elastoplastic properties of duplex steel determined using neutron diffraction and self-consistent model. Acta Mater. 2004, 52, 1133-1142. [CrossRef]

48. Bugat, S.; Besson, J.; Pineau, A. Micromechanical modeling of the behavior of duplex stainless steels. Comput. Mater. Sci. 1999, 16, 158-166. [CrossRef]

49. Jia, N.; Wang, Y.D.; Peng, L.R. Micromechanical behaviors of duplex steel: in situ neutron diffraction measurements and simulations. J. Phys. Condens. Matter 2008, 20, 104259. [CrossRef]

50. Song, J.L.; Bate, P.S. Plastic anisotropy in a superplastic duplex stainless steel. Acta Mater. 1997, 45, $2747-2757$. [CrossRef]

51. Fargas, G.; Akdut, N.; Anglada, M.; Mateo, A. Microstructural evolution during industrial rolling of a duplex stainless steel. ISIJ Int. 2008, 48, 1596-1602. [CrossRef]

52. Howard, R.E.; Lidiard, A.B. Matter transport in solids. Rep. Prog. Phys. 1964, 27, 161-240. [CrossRef]

53. Zhang, X.; Li, X.; Chen, W. Interfacial reactions of duplex stainless steels with molten aluminum. Surf. Interface Anal. 2015, 47, 648-656. [CrossRef]

54. Zhang, X.; Chen, W.; Luo, H.; Li, S.; Zhou, T.; Shi, L. Corrosion resistance and interfacial morphologies of novel Fe-Cr-Mo-B cast steels in molten aluminum. Corros. Sci. 2017, 125, 20-28. [CrossRef]

55. Yun, J.-G.; Lee, J.-H.; Kwak, S.-Y.; Kang, C.-Y. Microstructural Evolution of Intermetallic Compound Formed in Boron Steel Hot-Dipped in Al-7\%Ni Alloy. Metals 2017, 7, 393. [CrossRef]

56. Barmak, K.; Dybkov, V.I. Interaction of iron-chromium alloys containing 10 and 25 mass $\%$ chromium with liquid aluminium Part II Formation of intermetallic compounds. J. Mater. Sci. 2004, 9, 4219-4230. [CrossRef] 